\title{
The mechano-activated $\mathrm{K}^{+}$channels TRAAK and TREK-1 control both warm and cold perception
}

\begin{abstract}
Jacques Noël ${ }^{1,5, *}$, Katharina Zimmermann ${ }^{2,5}$, Jérome Busserolles ${ }^{3,4,5}$, Emanuel Deval ${ }^{1}$, Abdelkrim Alloui, ${ }^{3,4}$, Sylvie Diochot ${ }^{1}$, Nicolas Guy ${ }^{1}$, Marc Borsotto ${ }^{1}$, Peter Reeh ${ }^{2}$, Alain Eschalier ${ }^{3,4}$ and Michel Lazdunski ${ }^{1, *}$

${ }^{1}$ Université de Nice-Sophia Antipolis, CNRS UMR6097, Institut de Pharmacologie Moléculaire et Cellulaire, Institut Paul Hamel, Sophia Antipolis, Valbonne, France, ${ }^{2}$ Department of Physiology and Pathophysiology, University Erlangen-Nuremberg, Erlangen, Germany, ${ }^{3}$ Laboratoire de Pharmacologie Médicale, Faculté de Médecine/CHU, Clermont Université, Université d'Auvergne, Clermont-Ferrand, France and ${ }^{4}$ INSERM UMR766, Pharmacologie Fondamentale et Clinique, Faculté de Médecine, Clermont-Ferrand, France
\end{abstract}

The sensation of cold or heat depends on the activation of specific nerve endings in the skin. This involves heat- and cold-sensitive excitatory transient receptor potential (TRP) channels. However, we show here that the mechano-gated and highly temperature-sensitive potassium channels of the TREK/TRAAK family, which normally work as silencers of the excitatory channels, are also implicated. They are important for the definition of temperature thresholds and temperature ranges in which excitation of nociceptor takes place and for the intensity of excitation when it occurs. They are expressed with thermo-TRP channels in sensory neurons. TRAAK and TREK-1 channels control pain produced by mechanical stimulation and both heat and cold pain perception in mice. Expression of TRAAK alone or in association with TREK-1 controls heat responses of both capsaicin-sensitive and capsaicin-insensitive sensory neurons. Together TREK-1 and TRAAK channels are important regulators of nociceptor activation by cold, particularly in the nociceptor population that is not activated by menthol.

The EMBO Journal (2009) 28, 1308-1318. doi:10.1038/

emboj.2009.57; Published online 12 March 2009

Subject Categories: signal transduction; neuroscience

Keywords: background potassium channels; cold sensitization; heat sensitization; pain; thermo transduction; TRAAK; TREK-1

Identification of ion channels involved in peripheral nociceptor activation is essential to our understanding of mechanisms of pain perception (Julius and Basbaum, 2001;

\footnotetext{
${ }^{*}$ Corresponding authors. J Noël or M Lazdunski, Institut de Pharmacologie Moléculaire et Cellulaire, UMR CNRS 6097, CNRS-Université de Nice Sophia Antipolis, 660 Route des Lucioles, Valbonne 06560, France. Tel.: +33 4939577 20; Fax: +33493957708 or Tel.: +334939577 03; Fax: + 334939577 04; E-mail: jnoel@unice.fr or lazdunski@ipmc.cnrs.fr

${ }^{5}$ These authors contributed equally to this work
}

Received: 25 November 2008; accepted: 11 February 2009; published online: 12 March 2009
Abrahamsen et al, 2008). Background $\mathrm{K}^{+}$channels with two pore domains $\left(\mathrm{K}_{2 \mathrm{P}}\right)$ of the channel family composed of TREK1, TREK-2 and TRAAK are mechano- and temperature-gated (Maingret et al, 1999a, b, 2000a; Chemin et al, 2005; Kang et al, 2005). These channels are expressed in the dorsal root ganglion (DRG) neurons (Medhurst et al, 2001; Kang et al, 2005; Kang and Kim, 2006). TREK-1 was the first mechanoactivated $\mathrm{K}^{+}$channel to be recognized and it shows a 20-fold increase of activity when temperature rises from 22 to $42^{\circ} \mathrm{C}$ (Maingret et al, 1999b, 2000a; Chemin et al, 2005). TREK-1 is also activated by polyunsaturated fatty acids and by volatile anaesthetics (Patel et al, 1998, 1999). It is negatively regulated by $\mathrm{Gs}$ and $\mathrm{Gq}$ protein-coupled receptors, such as $\mathrm{PGE}_{2}$, serotonin and glutamate acting on metabotropic receptors (Chemin et al, 2003; Murbartian et al, 2005). We have recently reported that TREK-1 ${ }^{-/-}$mice show mechanical allodynia and that TREK-1 is also a molecular sensor for the perception of noxious heat (Alloui et al, 2006).

Similar to TREK-1, TRAAK is a mechano-gated $\mathrm{K}^{+}$channel (Maingret et al, 1999a). It is activated by polyunsaturated fatty acids but is insensitive to volatile anaesthetics (Fink et al, 1998; Patel et al, 1999; Maingret $\mathrm{F}$ et al, 2000b). TRAAK is active at physiological body temperature, shows a $\sim 12$ - to 20 -fold increase of activity when temperature rises from 17 to $\sim 40^{\circ} \mathrm{C}$ (Kang et al, 2005) (Supplementary Figure 2). Maximal activity is reached between 37 and $42^{\circ} \mathrm{C}$ and activity falls sharply at higher temperatures. Therefore, TRAAK, as TREK-1, stands as a strong candidate to regulate sensory neurons excitability in response to temperature and mechanical stimuli.

Several members of the transient receptor potential (TRP) channel family have been implicated in peripheral thermal sensation (Voets et al, 2004; Dhaka et al, 2006). Among these, the capsaicin receptor TRPV1 senses heat between 42 and $50^{\circ} \mathrm{C}$ and has been proposed as a noxious heat-sensor for nociceptors (Caterina et al, 2000). However, although it is clearly shown that TRPV1 participates in pain perception in primary inflammatory conditions (Caterina et al, 2000), TRPV1-deficient mice have been shown to have normal heat response at temperatures below $50^{\circ} \mathrm{C}$ in the absence of inflammation (Woodbury et al, 2004). Therefore, other ion channels have to be involved in heat-induced pain.

Cold activates two other members of the TRP channel family, the receptor for menthol, TRPM8 (Voets et al, 2004; Reid, 2005; Dhaka et al, 2006), and the receptor for pungent irritants from mustard and garlic, TRPA1/ANKTM1 (Story et al, 2003; Bautista et al, 2006; Kwan et al, 2006). The function of TRPM8 as a major physiological sensor for cold is now well established (Bautista et al, 2007; Colburn et al, 2007; Dhaka et al, 2007). However, cold sensitivity is not completely abolished in TRPM8-deficient mice, which implies the existence of additional cold-sensors in peripheral neurons (Reid and Flonta, 2001a, b; Viana et al, 2002; Munns et al, 2007). Although TRPA1 is sensitive to strong cooling below $17^{\circ} \mathrm{C}$, its function as a noxious cold sensor has been 
A

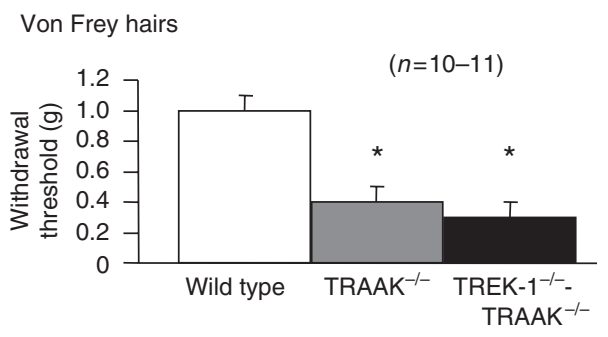

B Hypertonicity

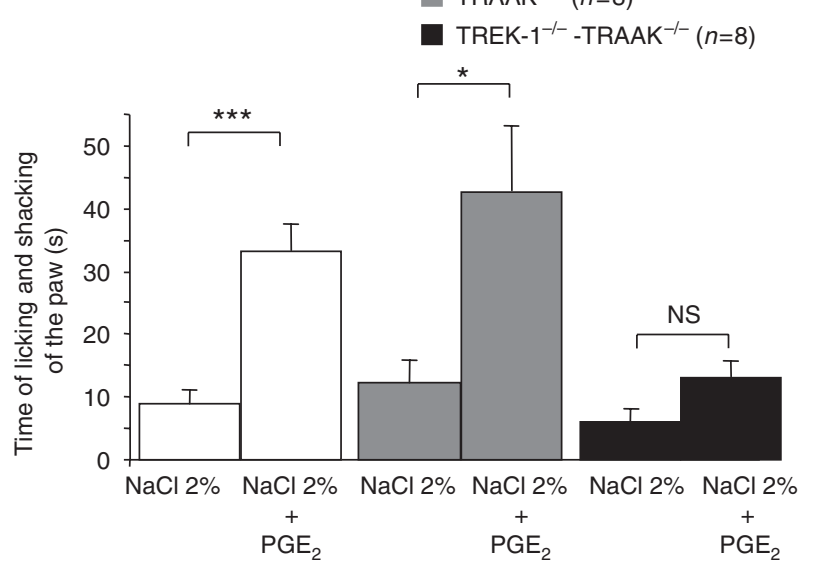

Figure 1 Mechanical allodynia in $\mathrm{TRAAK}^{-/-}$and $\mathrm{TREK}^{-/-}$. TRAAK $^{-1-}$ mice. (A) Mechanical sensitivity was measured on mice of indicated genotypes with paw withdrawal thresholds to von Frey hairs of increasing stiffness. (B) Intradermal injection of hypertonic saline $(\mathrm{NaCl} 2 \%)$ caused moderate nociceptive behaviour in wild-type, TRAAK ${ }^{-/-}$and TREK $1^{-1-}$-TRAAK ${ }^{-1-}$ mice. Sensitization with $\mathrm{PGE}_{2}(5 \mu \mathrm{M})$ potentiated the hypertonicity-induced nociceptive behaviour in wild-type and TRAAK ${ }^{-1-}$ mice, but was not effective in the TREK1 ${ }^{-/-}$TRAAK $^{-1-}$ mice. Values are mean \pm s.e.m. NS: not significant. Stars mark significant difference, with one star for $P<0.05$ and three stars for $P<0.001$; ANOVA with Tuckey's post-test.

debated, as studies of cold pain perception of TRPA1-deficient mice have led to opposite observations (Bautista et al, 2006; Kwan et al, 2006; Karashima et al, 2009). TRPA1, however, appears to be a major contributor of cold sensing in vagal afferent fibers and trigeminal ganglion neurons (Fajardo et al, 2008; Karashima et al, 2009). We analyse here the function of TRAAK and the combined functions of TREK- 1 and TRAAK channels in high- and low-temperature perception by nociceptors.

\section{Results}

\section{Mechanical allodynia of TRAAK ${ }^{-1}$ and TREK-1 ${ }^{-1-}$-TRAAK ${ }^{-/-}$mice}

The TREK- 1 and TRAAK channels are among the few channels for which a direct mechanical gating by membrane stretch has been shown (Maingret et al, 1999a, b). Here, we have also measured an increased mechanical sensitivity of TRAAK $^{-/-}$and TREK-1 ${ }^{-/-}$-TRAAK ${ }^{-/-}$mice (Figure 1). In behavioural experiments, both TRAAK ${ }^{-/-}$and TREK-1 ${ }^{-/-}$$\mathrm{TRAAK}^{-/-}$mice showed very significant mechanical hypersensitivity with reduced paw withdrawal thresholds $(\sim 1 \mathrm{~g}$, $9.8 \mathrm{mN}$ in wild-type; and $0.40 \mathrm{~g}, 3.9 \mathrm{mN}$, and $0.31 \mathrm{~g}, 3 \mathrm{mN}$, respectively, for TRAAK $^{-/-}$and TREK- $^{-/-}-$TRAAK $^{-1-}$ mice).

\section{Loss of sensitivity to osmotic pain in TREK-1 ${ }^{-1-}$-TRAAK ${ }^{-1-}$ mice but not TRAAK ${ }^{-1-}$ mice}

Hypodermic injection of hypertonic saline to stimulate primary afferent nociceptors associated with sensitization by $\mathrm{PGE}_{2}$ is a widely used model of pain in humans (AlessandriHaber et al, 2005). We tested the sensitivity of TRAAK $^{-/-}$and TREK- $1^{-/-}$-TRAAK ${ }^{-/-}$mice to subcutaneous injection of $\mathrm{NaCl} 2 \%$ in the hind paw. Saline injection provoked moderate pain in both knockouts and wild-type mice (Figure 1B), but after sensitization with $\mathrm{PGE}_{2}$, the pain sensation caused by the hypertonic solution was considerably and similarly increased in both wild-type and TRAAK ${ }^{-/-}$mice, showing that TRAAK is not involved in osmotic pain. On the contrary and as observed previously for TREK-1 ${ }^{-/-}$mice (Alloui et al, 2006), PGE2 did not sensitize TREK-1 $1^{-/-}$-TRAAK ${ }^{-/-}$mice to pain induced by hypertonic saline.

\section{TREK-1 and TRAAK channels silence heat nociceptors}

We used fluorescence calcium imaging to measure the sensitivity to noxious-heat and capsaicin of small diameter $(<20 \mu \mathrm{m})$ DRG neurons in culture (Figure 2A). In wild type, $34 \%$ of neurons responded to noxious heat (from 30 to $\sim 48^{\circ} \mathrm{C}$ ). This percentage was considerably increased in knockout mice to $60 \%$ in $\mathrm{TRAAK}^{-/-}, 64 \%$ in TREK-1 ${ }^{-/-}$ and $74 \%$ in TREK- $1^{-/-}$-TRAAK ${ }^{-/-}$mice. The percentage of neurons activated by both heat and capsaicin was essentially the same in wild-type, TRAAK ${ }^{-/-}$and TREK- $1^{-/-}$mice, but was substantially increased in TREK- $1^{-/-}$-TRAAK ${ }^{-/-}$ mice (Figure 2A). This did not result from a change of RNA expression for the capsaicin receptor, TRPV1 (Supplementary Figure 6). The percentage of neurons activated by heat but not by capsaicin was considerably increased after deletion of TREK-1, TRAAK and both TREK-1 and TRAAK channels.

The sensitivity to heat of skin C-mechano-nociceptors, which represent more than $90 \%$ of $\mathrm{C}$-fibres innervating the skin (Wetzel et al, 2007), was measured with the nerve-skin preparation (Reeh, 1986). The fraction of C-fibres activated by warming from 30 to $50^{\circ} \mathrm{C}$ increased from $56 \%$ in the wildtype to $70 \%$ in TRAAK $^{-1-}$ and $71 \%$ in TREK- ${ }^{-1-}$-TRAAK $^{-1-}$ mice, nearly identical to $73 \%$ of fibres that was previously reported for the TREK- $1^{-1-}$ fibres (Alloui et al, 2006) (Figure 2B). In all the deficient mice, the unsilencing of heat fibres was associated with a near proportional reduction in the fraction of mechano sensitive-thermo insensitive C-fibres (C-M fibres) (Supplementary Figure 3). On average, wild-type C-fibres fired a total of $14 \pm 4$ spikes ( $n=31$ fibres) during a heat ramp from 30 to $50^{\circ} \mathrm{C}$, TRAAK $^{-1-}$ C-fibres had $27 \pm 6$ spikes $(n=27)$ and TREK- $1^{-1-}$-TRAAK $^{-1-}$ C-fibres had $22 \pm 5$ spikes $(n=34 ; P<0.001$ wild-type versus TRAAK $^{-1-}$ or TREK- ${ }^{-1-}-$ TRAAK $^{-/-}$, Friedman test, Dunn's post hoc multiple comparison test) (Figure 2C). The response to heat was not amplified in the TREK- $1^{-/-}$-TRAAK ${ }^{-/-}$fibres compared with the TRAAK ${ }^{-/-}$fibres $\left(P>0.05\right.$ TRAAK $^{-/-}$ versus TREK- $1^{-/-}$-TRAAK ${ }^{-/-}$, Friedman test with Dunn's post hoc test). For temperatures above $46^{\circ} \mathrm{C}$, the difference between wild-type and TRAAK ${ }^{-1-}$ or TREK-1 ${ }^{-1-}$-TRAAK ${ }^{-1-}$ C-fibres progressively disappeared. One important effect of the deletion of TRAAK or both TREK-1 and TRAAK channels was the reduction of the heat-threshold temperature compared with wild-type $\left(41.1 \pm 0.7^{\circ} \mathrm{C}\right.$ for wild-type, $38.3 \pm 0.8^{\circ} \mathrm{C}$

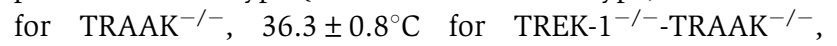
$P<0.05$ and $P<0.001$, respectively, over wild-type, ANOVA, 
A Heat-sensitive DRG neurons

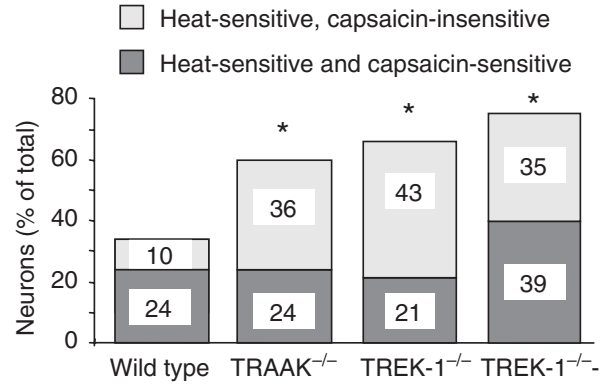

B

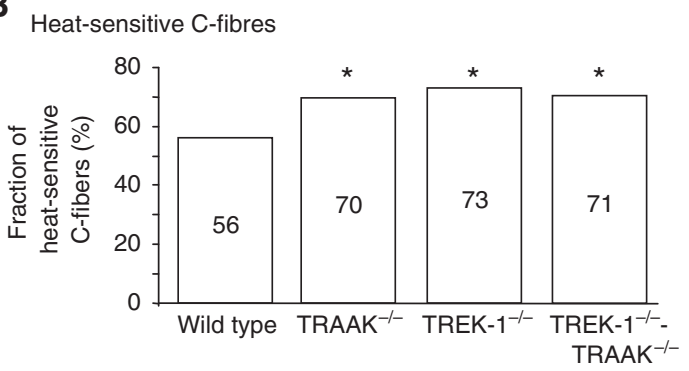

C
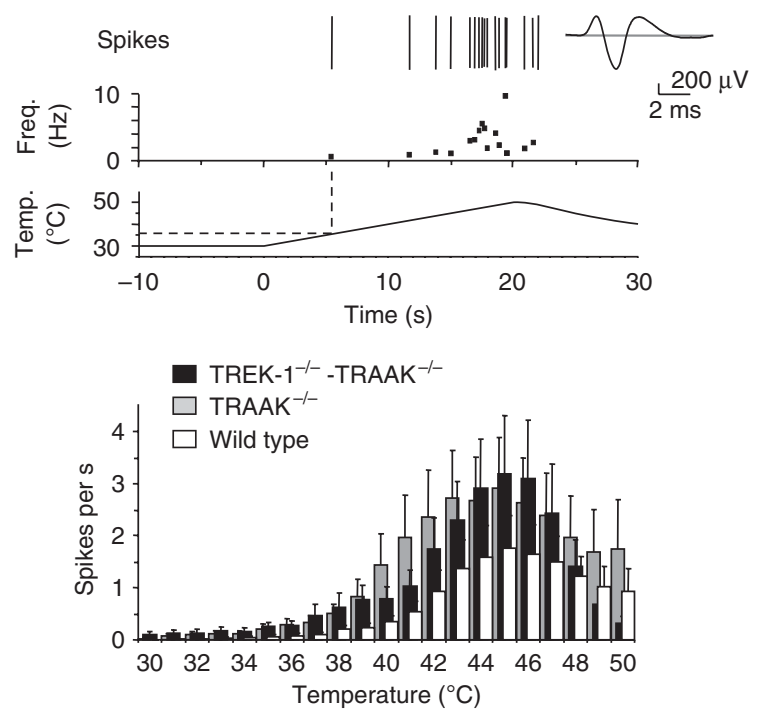

Figure 2 Enhanced heat sensitivity of TRAAK ${ }^{-/-}$, TREK $1^{-/-}$and TREK $1^{-/-}$-TRAAK ${ }^{-1-}$ DRG neurons and C-fibres. (A) Fractions of heat $\left(\sim 48^{\circ} \mathrm{C}\right)$-sensitive DRG neurons cultured from wild-type (338 neurons, 19 separate measures), TRAAK $^{-/-}$(182 neurons, 16 separate measures), TREK-1 $1^{-/}$(200 neurons, 13 separate measures) and TREK- $1^{-/-}$-TRAAK ${ }^{-/-}$mice ( 80 neurons, 8 separate measures). Light grey shows the fractions of heat-sensitive capsaicin-insensitive neurons. Dark grey shows the fractions of heat- and capsaicin-sensitive neurons. (B) Proportions of heat-sensitive C-fibres in wild-type $(n=78)$, TRAAK ${ }^{-1-}(n=40)$, TREK- $1^{-1-}$ $(n=41)$ and TREK $1^{-1-}$-TRAAK ${ }^{-/-}(n=75)$ mice measured in nerve-skin experiments. (C) Top: a representative experiment from a TREK $1^{-/-}$-TRAAK ${ }^{-/-}$C-fibre with its frequency plot, showing action potentials (Spikes) in response to the noxious heat ramp shown below. The average action potential is presented on the right. Bottom: histogram of averaged heat responses of wild-type, TRAAK $^{-/-}$and TREK $1^{-/-}$-TRAAK ${ }^{-/-}$C-fibres. Values are mean \pm s.e.m. One star marks $P<0.05$ over wild type; $\chi^{2}$ test.

Tukey's multiple comparisons post-test) (threshold temperature was assigned as the temperature of the first spike firing during a heat ramp) (Supplementary data). These effects associated with the deletion of TRAAK or both TREK-1 and
TRAAK channels are different from those observed on the same type of skin-nerve preparation after blockade of voltage-sensitive $\mathrm{K}^{+}$channels, $\mathrm{Ca}^{2+}$-activated $\mathrm{K}^{+}$channels and inward rectifier $\mathrm{K}^{+}$channels by 4-aminopyridine and tetraethylammonium, as none of these treatments altered the sensitivity of nerve endings to thermal stimuli (Kirchhoff et al, 1992).

\section{TRAAK $^{-/}$and TREK-1 ${ }^{-/-}$-TRAAK ${ }^{-1}$ mice have heat-hyperalgesia}

In the tail immersion test, TRAAK ${ }^{-1-}$ mice showed significant heat-hyperalgesia at temperatures between 46 and $50^{\circ} \mathrm{C}$ (Figure $3 \mathrm{~A}$ ). This window of temperature was larger in the TREK- $1^{-/-}$-TRAAK ${ }^{-/-}$mice, with significant hyperalgesia from 44 to $50^{\circ} \mathrm{C}$. TREK- $1^{-/-}-\mathrm{TRAAK}^{-/-}$mice, but not $\mathrm{TRAAK}^{-1-}$ mice, also remained more sensitive than wild type at higher temperatures of 52 and $56^{\circ} \mathrm{C}$ in the hot-plate test with the paw (Supplementary Figure 4).

Inflammation and neuropathy that develops after nerve injury can lead to intense thermal hyperalgesia and allodynia (Bennett and Xie, 1988). We therefore examined heat-hyperalgesia in inflammation induced by intraplantar injection of carrageenan and neuropathy induced by chronic constriction injury of the sciatic nerve. Both inflammation and neuropathy produced a very significant heat hyperalgesia of the paw at $46^{\circ} \mathrm{C}$ in wild-type mice (Figure $3 \mathrm{~B}$ and $\mathrm{C}$ ). Interestingly, the heat-hyperalgesia that resulted from the deletion of TRAAK or both TREK-1 and TRAAK channels was very similar in intensity to the hyperalgesia induced by inflammation and neuropathy in wild-type mice. Also, inflammation and neuropathy produced even more pain in both $\mathrm{TRAAK}^{-/-}$and TREK-1 ${ }^{-/-}$-TRAAK ${ }^{-/-}$mice.

\section{TRAAK and TREK-1 channels together are important for cold sensation}

As the activities of both TREK-1 and TRAAK channels are drastically decreased at low temperatures $\left(<17^{\circ} \mathrm{C}\right)$, we have investigated the cold sensitivity of DRG neurons and C-fibres from wild-type and knockout mice. We have first measured fluctuations of intracellular calcium in small diameter-cultured DRG neurons in response to sequential stimulations with noxious cold (down to $\sim 12^{\circ} \mathrm{C}$ ), menthol $(500 \mu \mathrm{M})$ and allyl-isothiocyanate (AI, $100 \mu \mathrm{M}$ ) as agonists for cold-gated TRPM8 and TRPA1 (Macpherson et al, 2006; Karashima et al, 2007) (Figure 4A and Supplementary Figure 2). In the wild type, $24 \%$ of DRG neurons were excited by cold, similar to previous reports (Story et al, 2003; Babes et al, 2004, 2006; Bautista et al, 2007; Munns et al, 2007). Deletion of $\mathrm{TRAAK}^{-1-}$ or TREK-1 ${ }^{-/-}$did not significantly change the fraction of cold-sensitive DRG neurons, with $23 \%$ of $\mathrm{TRAAK}^{-/-}$and $18 \%$ of TREK- $1^{-/-}$neurons. Conversely, a considerably increased fraction of cold-sensitive neurons was observed in TREK- $1^{-/-}$-TRAAK ${ }^{-/-}$neurons, reaching $54 \%$ of the total population of small-diameter DRG neurons. This was not due to an increase in the percentage of the neuronal population that is sensitive to both cold and menthol or cold and AI (Figure 4A and Supplementary Figure 2). The population that was most augmented was the cold-sensitive menthol and AI-insensitive neurons.

In parallel experiments, we observed that the fraction of cold-sensitive C-fibres in the skin of TREK- $1^{-/-}$and TRAAK $^{-/-}$mice was not significantly changed compared 
A

Heat hyperalgesia in the tail immersion test $(n=14-15)$

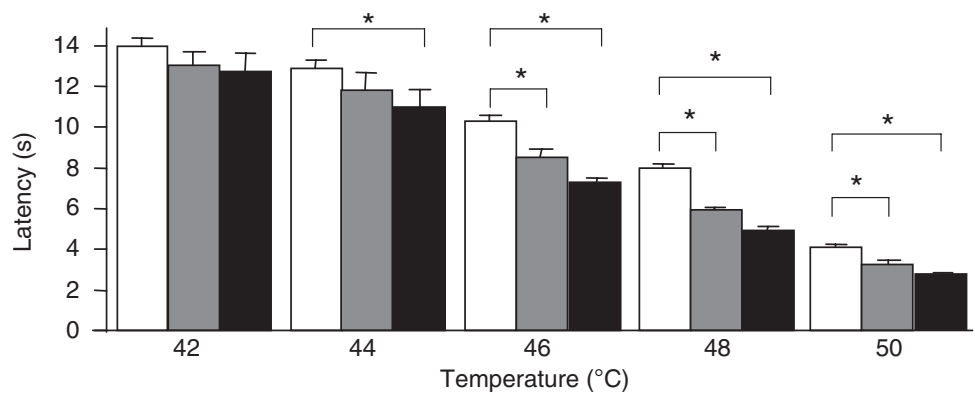

B Heat hyperalgesia in inflammation

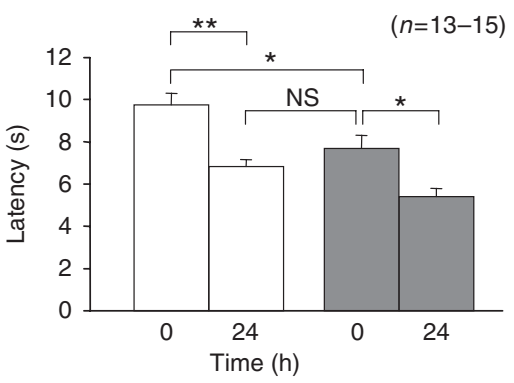

C Heat hyperalgesia in $\mathrm{CCI}$ neuropathy

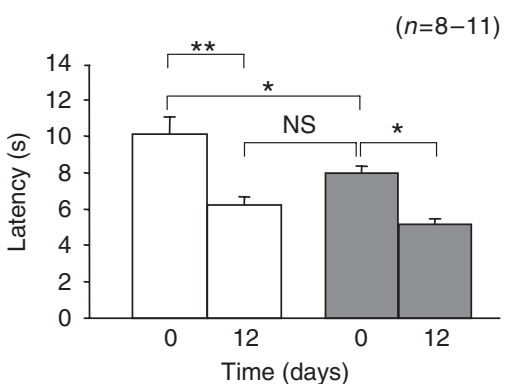

Paw withdrawal latencies from $46^{\circ} \mathrm{C}$ bath
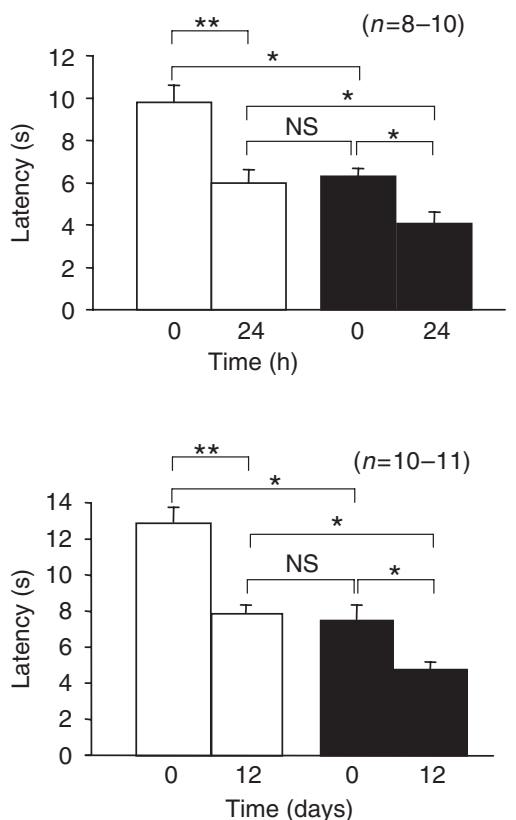

Figure 3 Heat hyperalgesia of TRAAK ${ }^{-1-}$ and TREK-1 $1^{-1-}$-TRAAK ${ }^{-1-}$ mice in normal and pathological conditions. (A) Tail immersion test at increasing bath temperatures on wild-type, TRAAK ${ }^{-/-}$and TREK-1 $1^{-1-}$-TRAAK ${ }^{-/-}$mice. (B) Measures of heat hyperalgesia of the paw before (time 0 ) and at $24 \mathrm{~h}$ of carrageenan-induced inflammation of the paw. The inflamed paw was immersed in a bath at $46^{\circ} \mathrm{C}$. (C) Measures of heat hyperalgesia of the paw in a bath at $46^{\circ} \mathrm{C}$ before (time 0 ) and 12 days after chronic constriction of the sciatic nerve in wild-type, TRAAK ${ }^{-/-}$and TREK- $1^{-/-}$-TRAAK ${ }^{-1-}$ mice. Values are mean \pm s.e.m. Stars mark significant difference with $P<0.05$ for one star and $P<0.01$ for two stars. Two-way ANOVA, Tukey’s post-test.

with wild type (Figure 4B and Supplementary Figure 3). Conversely again, the fraction of cold-sensitive C-fibres from TREK- $1^{-/-}$-TRAAK ${ }^{-/-}$mice was found to be very significantly increased over wild type. In addition, the response of TREK-1 $1^{-/-}$-TRAAK ${ }^{-/-}$fibres to cooling from 30 to $10^{\circ} \mathrm{C}(21.8 \pm 4.5$ spikes $)$ was increased over $\mathrm{TRAAK}^{-/-}$ $(9.4 \pm 1$ spikes) and wild-type fibres $(8.7 \pm 2$ spikes $)$ $\left(P>0.05\right.$ wild type versus TRAAK $^{-/-}, P<0.001$ wild type versus TREK-1 ${ }^{-1-}-$ TRAAK $^{-1-}$, Friedman test with Dunn's multiple comparison test) (Figure 4C and D).

Cold-sensitive DRG neurons are believed to divide into two populations with different temperature thresholds. Some neurons are sensitive to moderate cooling between skin temperature and $\sim 18^{\circ} \mathrm{C}$, and other neurons, believed to be nociceptive, respond to temperatures below $17^{\circ} \mathrm{C}$ (Reid, 2005). This is in good agreement with the bimodal distribution of cold thresholds observed in wild-type C-fibres. We identified a group of high-threshold temperatures fibres, with a dominant spiking-threshold mode around $23-25^{\circ} \mathrm{C}$ (mode 1), and a second group of C-fibres with a dominant threshold mode around $17^{\circ} \mathrm{C}(\sim 39 \%$ of cold fibres with threshold about and below $17^{\circ} \mathrm{C}$ ) (mode 2, Figure 4E). Interestingly, in TREK-1 ${ }^{-/-}$-TRAAK ${ }^{-/-}$mice, the group of low-threshold temperature fibres (mode 2 ) nearly completely disappeared and all C-fibres thresholds were shifted to higher temperatures between 30 and $\sim 18^{\circ} \mathrm{C}$.

We then tested the cold sensitivity of knockout mice in the cold plate assay and the temperature preference test. In good agreement with observations on cultured DRG neurons and C-fibres, TRAAK ${ }^{-/-}$mice showed no difference with wildtype mice in their sensitivity to cold in the cold plate assay (Figure 5A). On the contrary, TREK- $1^{-/-}$-TRAAK ${ }^{-1-}$ mice showed increased sensitivity to cold at 20,15 and $10^{\circ} \mathrm{C}$. At $5^{\circ} \mathrm{C}$, no difference was observed between mice strains. We then measured the aptitude of the mice to discriminate cold temperatures in a test of thermal-plate preference in 
A Cold-sensitive DRG neurons

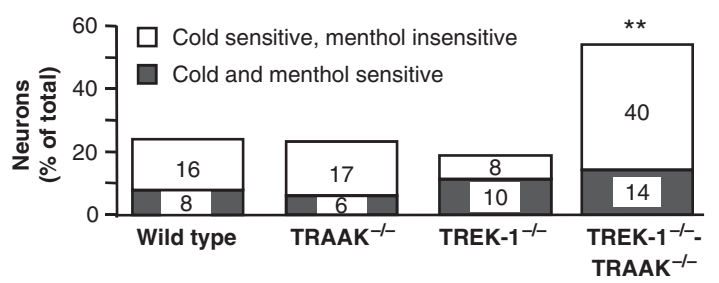

B Cold-sensitive C-fibres
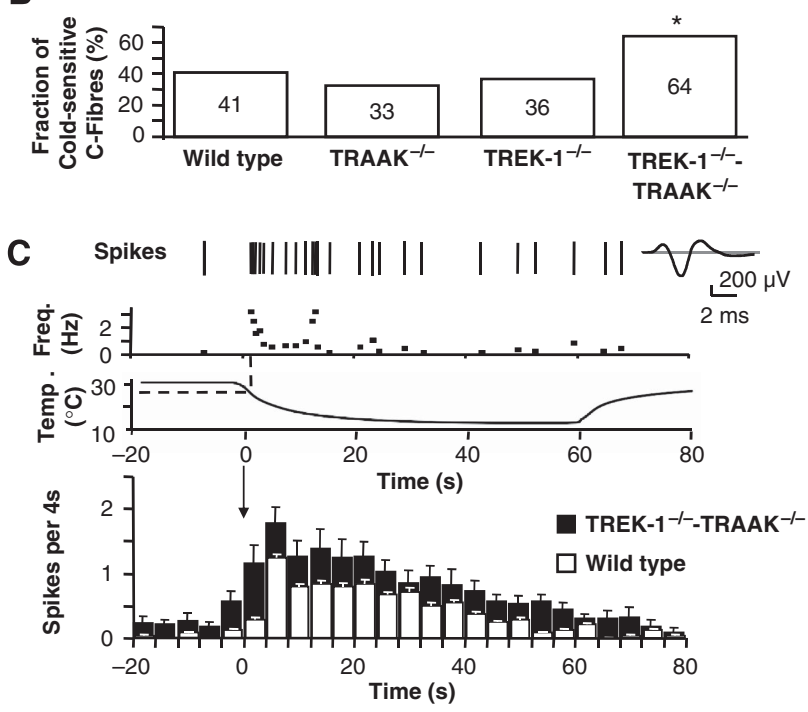

D
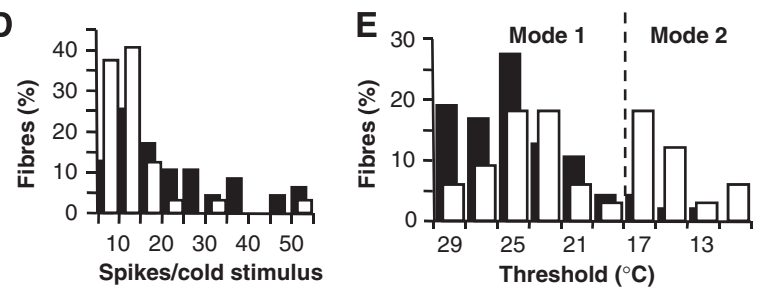

Figure 4 Cold sensitivity of DRG neurons and C-fibres of TRAAK ${ }^{-/-}$ and TREK $1^{-/-}$-TRAAK ${ }^{-/-}$mice. (A) Proportions of cultured DRG neurons sensitive to cooling between 30 and $12^{\circ} \mathrm{C}$, from wild-type, TRAAK ${ }^{-1-}$, TREK- $1^{-1-}$ and TREK- ${ }^{-1-}-$ TRAAK $^{-1-}$ mice. Fractions are shown of cold- and menthol-sensitive neurons (light grey) and cold-sensitive and menthol-insensitive neurons (white). Two stars for $P<0.01 ; \chi^{2}$ test. (B) Proportion of cold-sensitive C-fibres in the skin of wild-type $(n=78)$, TRAAK ${ }^{-1-}(n=40)$, TREK- $1^{-1-}(n=41)$ and TREK- $1^{-/}-$TRAAK $^{-1-}$ mice $(n=75)$. The star for $P<0.05 ; \gamma^{2}$ test. (C) A representative response of a TREK1 ${ }^{-1-}-\mathrm{TRAAK}^{-1-} \mathrm{C}$-fibre to a cold stimulus with its frequency plot. Action potentials (spikes) are shown with their average. Bottom: average histogram $(4 \mathrm{~s}$ bin, mean \pm s.e.m.) of wild-type (white-bar) and TREK1 ${ }^{-1-}$-TRAAK ${ }^{-1-}$ (dark bars) C-fibre responses to a $60 \mathrm{~s}$ cooling pulse from 30 to $10^{\circ} \mathrm{C}$, shown above. (D) Relative frequency distribution plot of wild-type and TREK1 ${ }^{-/}-$TRAAK $^{-/}-$C-fibre response to cold. Class interval 5 spikes. (E) Relative frequency distribution plot of cold thresholds of $\mathrm{C}$-fibres from wild-type and TREK1 ${ }^{-1-}-\mathrm{TRAAK}^{-1-}$ mice. Class interval $2^{\circ} \mathrm{C}$.

which mice move freely between two plates set at different temperatures (Figure 5B). The temperature of one plate was held at $30^{\circ} \mathrm{C}$, whereas the second plate was set at decreasing temperatures. Mice avoided the plate at cooler temperature that caused discomfort or pain. Obviously mice showed no preference when the two plates were set at $30^{\circ} \mathrm{C}$, but, as the temperature of one of the plates was lowered, TREK- $1^{-/-}$$\mathrm{TRAAK}^{-/-}$mice, but not $\mathrm{TRAAK}^{-/-}$mice, started to avoid

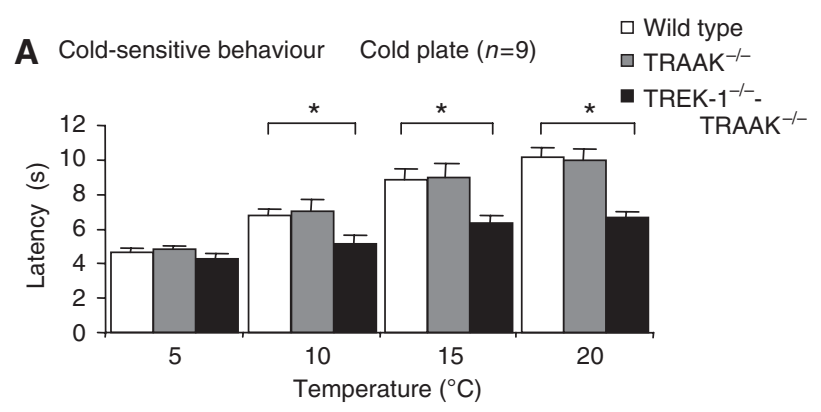

B Cold avoidance Thermal preference $(n=5-10)$

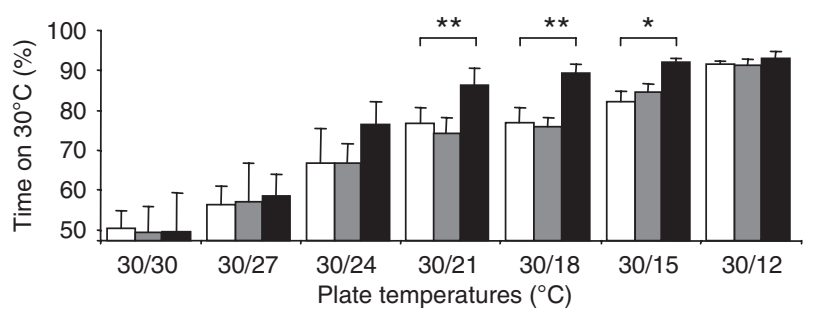

C

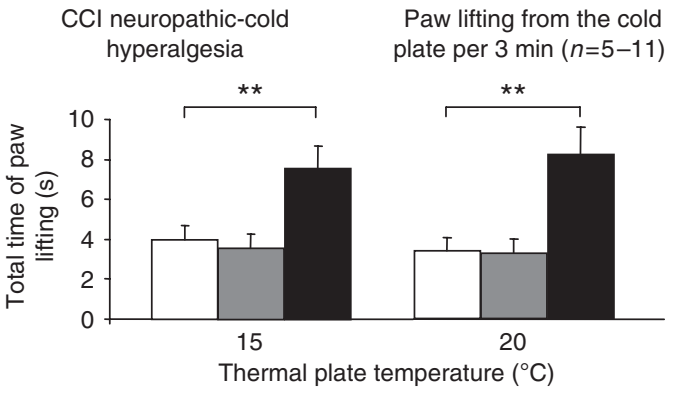

Figure 5 Cold-sensitive behaviour of wild-type, TRAAK $^{-/-}$and TREK-1 ${ }^{-/-}$-TRAAK ${ }^{-/-}$mice in normal and CCI neurophatic conditions. (A) Nocifensive cold-plate test showing reduced latency of TREK- ${ }^{-1-}$-TRAAK ${ }^{-1-}$ mice. The temperature of the plate is indicated in the graph. (B) Thermal discrimination test with two temperature plates. The temperature of one of the plates was maintained at $30^{\circ} \mathrm{C}$ and the temperature of the second plate was set as indicated. The time indicated is the fraction of time spent by the mice on the $30^{\circ} \mathrm{C}$ plate measured over $3 \mathrm{~min}$. (C) Cold allodynia of CCI neuropathic wild-type, TRAAK ${ }^{-/-}$and TREK- $1^{-1-}-$ TRAAK $^{-1-}$ mice measured as the total time of lifting of the paw over $3 \mathrm{~min}$ when mice were placed on a cold plate at 15 and $20^{\circ} \mathrm{C}$. Values are mean \pm s.e.m. Stars mark significant differences, with one star for $P<0.05$ and two stars for $P<0.01$; two-way ANOVA with Tukey's post-test.

the colder plate significantly more than wild-type mice. This was particularly significant at temperatures of 21,18 and $15^{\circ} \mathrm{C}$. TREK- $1^{-/-}$mice showed a difference with wild-type mice for temperature discrimination between 30 and $18^{\circ} \mathrm{C}$ (Supplementary Figure 7). The difference between wild-type and knockout mice cannot be analysed at lower temperatures, such as $12^{\circ} \mathrm{C}$. The temperature difference between 30 and $12^{\circ} \mathrm{C}$ is too high and all mice, independent of their genotype, spend more than $90 \%$ of the time on the plate at $30^{\circ} \mathrm{C}$.

As neuropathy is a common cause of cold allodynia (Bennett and Xie, 1988), we compared, using another test, cold allodynia in knockout and wild-type mice in the CCI model of neuropathy. After 12 days of sciatic nerve constriction, mice were placed on a cold plate and the time of paw lifting was measured over $3 \mathrm{~min}$. Neuropathic TRAAK $^{-/-}$and 
wild-type mice showed no difference in their cold sensitivity (Figure 5C). On the contrary, neuropathic TREK- $1^{-/-}$TRAAK $^{-1-}$ mice showed a marked cold hypersensitivity compared with wild-type and TRAAK ${ }^{-/-}$mice at both 15 and $20^{\circ} \mathrm{C}$.

\section{Discussion}

TREK-1 and TRAAK channels are mechano- and temperaturesensitive (Patel et al, 1998; Maingret et al, 1999a, b, 2000a; Chemin et al, 2005; Kang et al, 2005). They are expressed in DRGs (Medhurst et al, 2001; Kang et al, 2005) and therefore, similar to TRPV1 and TRPM8, they are obvious candidates for sensory perception.

Previous work has strongly suggested that the TREK-1 channel is associated with both heat and mechano-sensing (Alloui et al, 2006). This article analyses in more detail the mechanism underlying the function of TREK-1 in noxiousheat perception, but it is particularly focused on the sensory function of the TRAAK channel and the coordinated sensory function of both TREK-1 and TRAAK channels.

TRAAK being mechano-sensitive, similar to TREK-1, it was not surprising to find that TRAAK $^{-/-}$mice were hypersensitive to mechanical stimulation in the von Frey assay. This hypersensitivity was further increased when both TREK-1 and TRAAK channels were deleted. This important decrease of withdrawal threshold in both TRAAK ${ }^{-/-}$and TREK- ${ }^{-/-}$. TRAAK $^{-/-}$animals corresponds to mechanical allodynia. The mechanism proposed for this increased mechano-sensitivity is shown in Figure 6A. It suggests that stretch normally activates in a coordinated way both mechano-sensitive excitatory $\mathrm{Na}^{+}$-permeable channels that have not yet been clearly identified in molecular terms (Abrahamsen et al, 2008) and the hyperpolarizing TREK-1, TRAAK or both TREK-1 and TRAAK $\mathrm{K}^{+}$channels. It suggests that it is the balance between these two types of channels that defines the exact mechanical threshold for activation of nociceptors. Evidently, removal of the TREK-1, TRAAK or both TREK-1 and TRAAK channels relieves the inhibitory part in this functional assembly of channels and shifts the threshold for noxious mechano-perception to lower values.

Another view, of course, could be that deletion of any of the many neuronal $\mathrm{K}^{+}$channels in nociceptors might depolarize sensory neurons, facilitate the generation of action potentials and trigger painful sensations in all pain assays. We are clearly not in such a situation as a deletion of both TRAAK and TREK-1 channels that highly sensitizes to mechanical pain, in contrast, reduces osmotic pain. It is clear therefore that the increased responses to mechanical stimulations and, as discussed below, to heat or cold, are not related to a 'non-specific' effect associated with inhibition of $\mathrm{K}^{+}$ channels.

Another interesting observation relative to osmotic pain, which is known to be associated with inflammation and diabetic-induced neuropathy (Matsuka and Spigelman, 2004), is that the TREK- $1^{-/-}$-TRAAK ${ }^{-/-}$mice behave similar to TREK-1 ${ }^{-/-}$mice (Alloui et al, 2006). Deletion of the TRAAK channel has no effect on the noxious perception of hypertonic saline with or without previous sensitization with $\mathrm{PGE}_{2}$. Therefore, the TREK-1 but not the TRAAK channel is involved in osmotic sensing. The TREK-1 and the TRAAK channels are both mechano- and temperature-sensitive
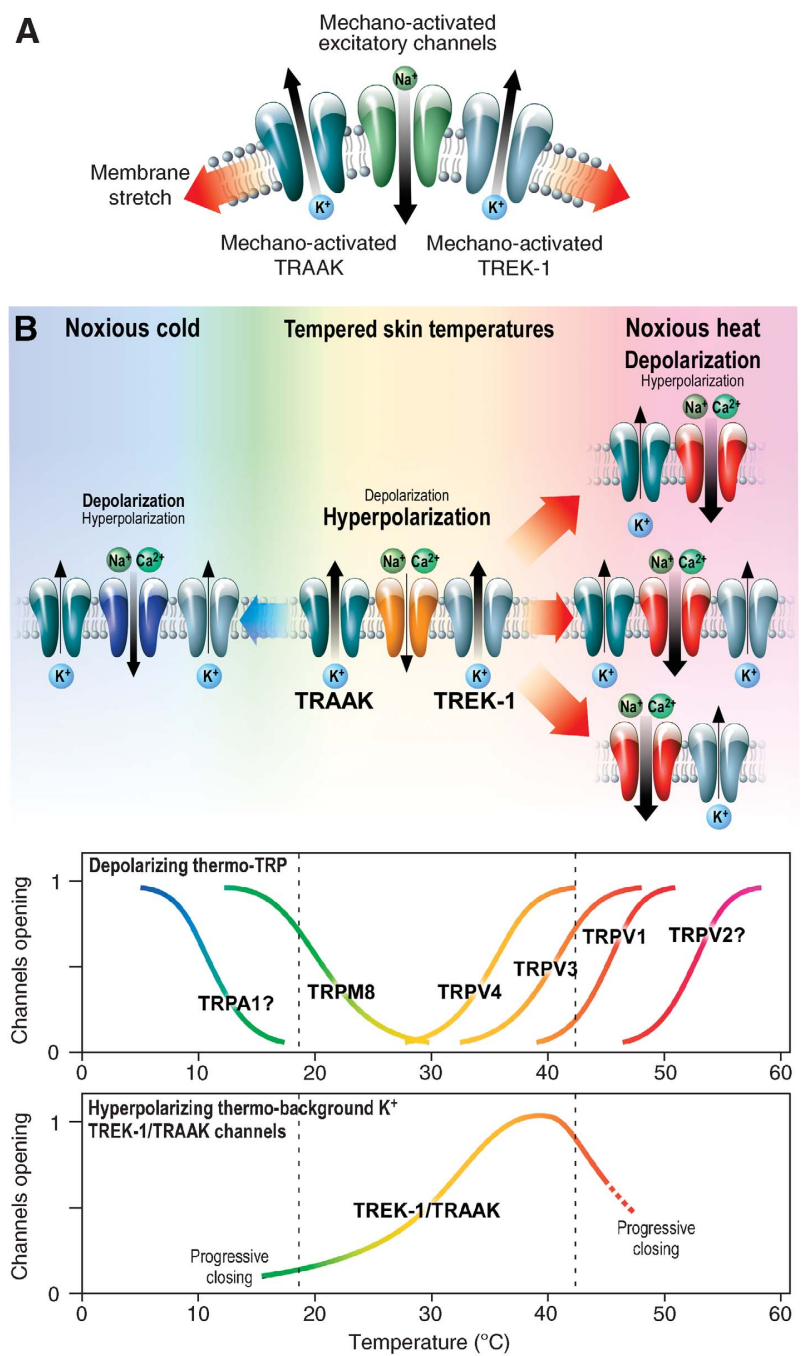

Figure 6 Mechano- and thermo-sensitive TREK-1 and TRAAK channels work in concert with and oppose depolarization induced by mechano-and thermo-sensitive excitatory channels in nociceptors. (A) Membrane stretch opens TREK-1 and TRAAK hyperpolarizing channels. Above a noxious and potentially tissue-damaging threshold, mechano-activated depolarizing channels dominate TREK-1 and TRAAK channels to activate nociceptive neurons and produce pain. (B) At tempered skin temperatures, temperaturesensitive TREK-1 and TRAAK channels are opened, they hyperpolarize the plasma membrane and impose an inactivation of nociceptive neurons. Both noxious heat and noxious cold temperatures cause the progressive decline of the hyperpolarizing contribution of TREK-1 and TRAAK channels in front of the steep activation of warm-sensitive and cold-sensitive depolarizing channels. Excitatory channels can work in association either with TREK-1 or TRAAK channels alone or with the combination of the two $\mathrm{K}_{2 \mathrm{P}}$ channels. Thermal thresholds of pain (dashed line) in the warm or cold direction will depend on the type of associations between excitatory channels (most probably thermo-TRP channels) and the TREK-1 and TRAAK channels.

channels, but they differ in many other ways (Patel et al, 1999; Maingret et al, 1999b; Chemin et al, 2003; Murbartian et al, 2005) and the protein partners that associate with the TREK-1 channels do not associate with the TRAAK channel (Sandoz et al, 2006, 2008).

This work mainly investigates how TRAAK alone or together with TREK-1 contributes to sensing warmth and cold. It particularly shows that these two channels together are essential molecular entities for cold sensing. 
Properties of heat-sensitive DRG neurons were first studied by $\mathrm{Ca}^{2+}$ imaging. The population of small DRG neurons comprises two types of sensory neurons that respond to temperature increase between 30 and $\sim 48^{\circ} \mathrm{C}$. The major type in wild-type mice represents $24 \%$ of small DRG neurons and is both heat- and capsaicin-sensitive. The other type represents about $10 \%$ of the neuronal population and is sensitive to heat but lacks capsaicin sensitivity. Removing TREK-1 or TRAAK channels drastically increases, by a factor of 3.5, the population of heat-activated, capsaicin-insensitive neurons. The final result being that after deletion of TREK-1 or TRAAK, $60-70 \%$ of DRG neurons, instead of $\sim 34 \%$ in wild type, are activated by warming to $48^{\circ} \mathrm{C}$. Clearly, the function of TREK-1 or TRAAK is to silence nociceptors to heat most probably by balancing the activity of other heat-sensitive excitatory channels. Deletion ofTREK-1 or TRAAK channels leads to unsilencing of heat-nociceptors. The mechanism by which this probably occurs is indicated in Figure 6B. In this scheme, neurons express both thermo-sensitive channels permeable to $\mathrm{Na}^{+}$that confer excitability and the thermosensitive $\mathrm{K}^{+}$channels TREK-1 and/or TRAAK channels that have an opposite effect. The temperature threshold of the heat nociceptor will be a function of the respective proportions of these two families of channels and of their respective temperature dependences. The population of DRGs that is heat-sensitive and capsaicin-insensitive most probably corresponds to the population of heat-sensitive IB4-positive neurons that do not express TRPV1 (Stucky and Lewin, 1999; Woodbury et al, 2004). What are then the thermo-sensitive depolarizing channels in the heat-sensitive and capsaicininsensitive neurons? Possibly the thermo-TRP channels TRPV3 and TRPV4 (Moqrich et al, 2005; Dhaka et al, 2006), but of course there could be other thermo-sensitive channels that have not yet been identified (Abrahamsen et al, 2008). Are the TREK-1 and TRAAK channels silencing the same or different populations of DRGs? The most probable answer is that they silence the same population of DRG neurons, as deletion of both TREK-1 and TRAAK channels in TREK- ${ }^{-/-}$-TRAAK ${ }^{-/-}$DRGs does not further increase the proportion of heat-sensitive and capsaicin-insensitive neurons. This particular population of neurons stays around $40 \%$. Conversely, the combined deletion of TREK-1 and TRAAK channels nearly doubles the population of heatsensitive capsaicin-sensitive neurons, whereas the individual deletions of TREK-1 or TRAAK do not change the proportion of these neurons. There is clearly a population of heat- and capsaicin-sensitive nociceptors that expresses TRPV1 and both TREK-1 and TRAAK. In these nociceptors, the presence of both TREK-1 or TRAAK is potent enough to completely neutralize the activation of TRV1 when temperature rises. These neurons from wild type remain silent up to $48^{\circ} \mathrm{C}$, although TRPV1 itself is activated with temperature thresholds below $40^{\circ} \mathrm{C}$ depending on membrane potential (Voets et al, 2004). This particular population of sensory neurons might not correspond to C-fibres, but to a fraction of A $\delta$-neurons. The criteria used to select neurons in culture, on the basis of their somatic diameters, also leads to analysis of small-diameter A $\delta$ neurons that are believed to represent $\sim 20 \%$ of DRG neurons (Lewin and Moshourab, 2004). This class of neurons is sensitive to heat but at higher temperatures than C-nociceptors (Treede et al, 1995).
How do the $\mathrm{Ca}^{2+}$ imaging results compare with those from the analysis of heat-sensitive C-fibres? Silencing of TREK-1 or of TRAAK channels increases the fraction of C-fibres that responds to variations of temperatures to $50^{\circ} \mathrm{C}$. Deleting TREK-1 or TRAAK channels obviously leads to activation between 30 and $50^{\circ} \mathrm{C}$ of a population of C-fibres $(\sim 15 \%$ of total) that otherwise would only be activated at temperatures higher than $50^{\circ} \mathrm{C}$. This is completely consistent with $\mathrm{Ca}^{2+}$ imaging results. Also, in line with previous interpretations, C-fibre recordings indicate that TREK-1 and TRAAK are expressed in the same DRGs, otherwise the effects would be additive in TREK- $1^{-/-}$-TRAAK ${ }^{-/-}$mice. The large effects of the removal of TREK-1 and TRAAK channels on the proportion of heat-sensitive and capsaicin-sensitive neurons observed by $\mathrm{Ca}^{2+}$ imaging are not observed when one analyses changes in C-fibre proportions. This would support the idea that the conversion of capsaicin-sensitive heatinsensitive neurons in culture into capsaicin-sensitive heatsensitive neurons by deleting both TREK-1 and TRAAK channels may concern $A \delta$ neurons that are normally in charge of detecting temperatures higher than $50^{\circ} \mathrm{C}$ but that are drastically changed in their temperature response, with decreased thresholds, when both TREK-1 and TRAAK are deleted. In fact, an extensive literature has raised questions about the role of TRPV1 in the perception of noxious temperatures above $42-43^{\circ} \mathrm{C}$, when we perceive a shift from anoxious warm to noxious heat (Stucky and Lewin, 1999; Woodbury et al, 2004; Dhaka et al, 2006). The work presented here clearly shows that when TRPV1, characterized by its capsaicin sensitivity, is present in sensory neurons with both TREK-1 and TRAAK channels, the firing of these neurons will not occur below $50^{\circ} \mathrm{C}$. These particular neurons will then be expected to fire only at higher temperatures. This could easily explain that TRPV1 $1^{-/-}$mice are particularly defective in thermal pain perception only in a range of temperatures higher than $52^{\circ} \mathrm{C}$ (Caterina et al, 2000).

We have clearly seen that deletion of TREK-1 or TRAAK and deletion of both TREK-1 and TRAAK channels unsilence neurons, which otherwise would not be activated by heat between 30 and $50^{\circ} \mathrm{C}$. But what are then the firing properties of this ensemble of neurons? Deletion of TREK-1, TRAAK and TREK-1-TRAAK channels produces two drastic changes in the properties of the heat-sensitive $\mathrm{C}$-fibres. The first one is a shift towards lower temperatures of the temperature threshold for firing by about $3-5^{\circ} \mathrm{C}$ both in TRAAK ${ }^{-/-}$and in TREK- $1^{-/-}$TRAAK $^{-/-}$mice as reported previously for the TREK-1 channel (Alloui et al, 2006). The second one is an increase of the firing properties of $\mathrm{C}$-fibres at all temperatures from 35 to $46^{\circ} \mathrm{C}$ for all knockout mice (Figure $2 \mathrm{C}$ ). Lower temperature thresholds and increased firing activity are of course consistent with the idea that removing a temperature-sensitive brake (TRAAK or TREK-1) or two temperature-sensitive brakes (both TRAAK and TREK-1), will have two consequences (Figure 6). The first effect is to bring the intrinsic temperature threshold of C-fibres nearer to the temperature threshold of the specific TRP (or TRP-like) channels in charge of the primary response to temperature increase. The second one is to decrease the balancing contribution of temperature-sensitive $\mathrm{K}^{+}$channels in the temperature range in which these temperature-sensitive excitatory channels are normally active, producing an increased activity of C-fibres of knockout animals at all temperatures to $\sim 50^{\circ} \mathrm{C}$, as indeed observed. 
The pain behaviour of $\mathrm{TRAAK}^{-/-}$and $\mathrm{TREK}^{-1}{ }^{-/}$TRAAK $^{-/-}$mice is completely consistent with previous considerations on the function of TREK-1 and TRAAK channels. In the tail immersion test, an increased pain is observed for both TRAAK $^{-/-}$and TREK- $1^{-/-}$-TRAAK ${ }^{-/-}$mice between 44 and $50^{\circ} \mathrm{C}$. The temperature threshold of heat perception is decreased in both types of mice in the tail immersion test (between 42 and $44^{\circ} \mathrm{C}$ ), although it does not exactly correspond to the thresholds seen in the C-fibres analysis (near $35-36^{\circ} \mathrm{C}$ ). This difference is due to the fact that pain perception is not linearly associated with C-fibres thresholds because (i) temperature applied on the tail is not a temperature imposed directly on C-fibres, (ii) pain perception is driven not only by the temperature thresholds, but also by the firing profile of $\mathrm{C}$-fibres.

In a second type of assay, thermal pain perception provoked by deletion of TRAAK and both TREK-1 and TRAAK channels has been compared with hyperalgesia produced by inflammation and by a neuropathic situation produced by chronic constriction injury. It is particularly interesting to see that the paw withdrawal latency at $46^{\circ} \mathrm{C}$ after deletion of TRAAK or both TRAAK and TREK-1 channels is nearly the same as for wild-type animals suffering from inflammatory or CCI-induced neuropathic pain. In addition, both inflammation and neuropathy further increase the pain already produced by deletion of TRAAK or TREK-1 and TRAAK channels.

All these results taken together clearly indicate the central function of temperature-sensitive TREK-1 and TRAAK channels in noxious heat perception. These two channels are essential molecular elements of the thermostat that defines threshold and firing activities in fibres associated with pain perception.

The past few years have changed our understanding of how warm and also cold are sensed by thermoreceptors and nociceptors, and four possible candidates have emerged as the main sensors of the cold transduction mechanism. They are (i) the cold and menthol-activated ion channel TRPM8, (ii) another TRP channel, TRPA1, that is activated by pungent irritants, (iii) a cationic channel generating $I_{\mathrm{h}}$ and a voltagesensitive $\mathrm{K}^{+}$channel generating $\mathrm{IK}_{\mathrm{D}}$, (iv) the temperaturesensitive background $\mathrm{K}^{+}$channel TREK-1 (Maingret et al, 2000a; Reid and Flonta, 2001a,b; Viana et al, 2002; Reid, 2005). Recent work with knockout mice has clearly established TRPM8 as an important but not unique physiological sensor of cold (Bautista et al, 2007; Colburn et al, 2007; Dhaka et al, 2007) but has not been conclusive for TRPA1 (Bautista et al, 2006; Kwan et al, 2006; Fajardo et al, 2008; Karashima et al, 2009) and has failed to show a clear function for the TREK-1 channel (Alloui et al, 2006). It is the reason why we analysed here the possible function of the TRAAK channel, another mechano-sensitive $\mathrm{K}^{+}$channels that gradually closes with steep temperature dependence below $30^{\circ} \mathrm{C}$, as well as the combined functions of the TRAAK and TREK-1 channels. $\mathrm{Ca}^{2+}$ imaging first showed, in accordance with previous work (Babes et al, 2004, 2006; Munns et al, 2007), that only a small population of DRGs $(\sim 8 \%)$ responds to both cold between 30 and $\sim 12^{\circ} \mathrm{C}$ and menthol while a larger population $(\sim 16 \%)$ is cold-sensitive but is insensitive to menthol. Deletion of individual TRAAK or TREK-1 channels did not radically alter the proportion of cold-sensitive and menthol-sensitive neurons $( \pm 2 \%$ around the $8 \%$ of wildtype neurons sensitive to cold and menthol). Overall, the deletion of TREK-1 or TRAAK did not change the fraction of DRG neurons that responded to cold, menthol and allylisothiocyanate (14\% in wild-type, 12 and $11 \%$, respectively, in TREK-1 ${ }^{-/-}$and TRAAK ${ }^{-/-}$DRGs) (Supplementary Figure 2). Conversely, the double deletion of TREK-1 and TRAAK produced significant changes in the population of neurons sensitive to menthol and cold, from 8 to $14 \%$ or to AI and cold, from 10 to $19 \%$. This is unlikely to result from an increase in expression of TRPM8 or TRPA1 as RNA levels for these channels were not changed in the TREK-1 ${ }^{-/-}$-TRAAK ${ }^{-/-}$ DRGs (Supplementary Figure 6). However, the major effect of this double deletion concerns the population of coldsensitive and menthol and AI-insensitive neurons, which increased by 2.5 times (Supplementary Figure 2). This is a clear demonstration that TREK-1 and TRAAK channels together, not individually, control cold perception. This view was totally confirmed by C-fibres recording. The proportion of mechano-sensitive $\mathrm{C}$-fibres responding to cold between 30 and $\sim 12^{\circ} \mathrm{C}$ was not very different in wild-type, TRAAK $^{-/-}$ and TREK- $1^{-1-}$ mice $(33-41 \%)$ but was much larger in TREK- $1^{-1-}$-TRAAK ${ }^{-1-}$ mice (64\%). Again, this is a clear indication that these two thermosensitive $\mathrm{K}^{+}$channels together normally silence a population of neurons in the wild type that would probably be active only at temperatures lower than $\sim 12^{\circ} \mathrm{C}$, that we have not reached in our assay because the contribution of TREK-1 and TRAAK is very low (Maingret et al, 2000a) (Supplementary Figure 1). Removal of the two channels together eliminates sufficient $\mathrm{K}^{+}$channel activity to unsilence nociceptors. The opening of cold-sensitive TRP channels or other types of excitatory cold-activated channels then becomes dominant (Figure 6B). This has two effects: the first one is a control of the size of the population of $\mathrm{C}$-fibres that is sensitive to cold down to $12^{\circ} \mathrm{C}$; as we have seen, the second is a control of the firing properties of coldsensitive $\mathrm{C}$-fibres between 30 and $12^{\circ} \mathrm{C}$. At these cold temperatures, the firing activity of TREK- $1^{-/-}$-TRAAK ${ }^{-/-}$ C-fibres is much higher than that of wild-type fibres. In wild-type, $79 \%$ of the $\mathrm{C}$-fibres fire a maximum of 10 spikes per cold stimulus, whereas in TREK- $1^{-/-}$-TRAAK ${ }^{-/-}$mice, $61 \%$ of the C-fibres fire between 10 and 50 spikes per cold stimulus.

Mild cooling induces cool sensations but stronger cooling can induce pain (Reid, 2005). While the cooling sensation is probably associated with a population of low threshold $\left(\sim 29^{\circ} \mathrm{C}\right)$ sensory neurons, cold-sensitive nociceptors are activated below $\sim 17^{\circ} \mathrm{C}$ and cooling near $15^{\circ} \mathrm{C}$ causes pain (Reid, 2005). Do TREK-1 and TRAAK channels together contribute to the cooling sensation or do they contribute to the painful sensation associated with exposure of nociceptors to lower temperatures, or do they contribute to both? Recording of C-fibres has identified two groups of fibres in the wild-type animal (Figure 4E). The first one has thresholds between 29 and $\sim 21^{\circ} \mathrm{C}$ and a majority of fibres with thresholds at $25-23^{\circ} \mathrm{C}$. The second group has thresholds between 19 and $\sim 13^{\circ} \mathrm{C}$ and a majority of fibres with thresholds at $17-15^{\circ} \mathrm{C}$. The first population of fibres is probably associated with a cooling sensation, whereas the second one probably associated with unpleasant or painful sensations. In TREK- $1^{-/-}$-TRAAK ${ }^{-/-}$mice, this second population of neurons seems to disappear. In fact, it is converted to a population with much higher temperature thresholds in the $20-29^{\circ} \mathrm{C}$ temperature range. Deletion of the TREK-1 
and TRAAK channels probably also induces a shift of the thresholds of the first population of fibres, which would be expected to result in a more intense perception of the cooling sensation at higher temperatures. This interpretation is in line with $\mathrm{Ca}^{2+}$ imaging experiments, showing that deletion of both TREK-1 and TRAAK channels reveals an additional population of neurons that are menthol- and cold-sensitive. The presence of both TREK-1 and TRAAK in TRPM8-containing neurons certainly contributes to silence this excitatory channel in a large temperature range.

For unpleasant and painful cold perception, the most interesting population of $\mathrm{C}$-fibres is the one with a temperature threshold below $17^{\circ} \mathrm{C}$. After deletion of both TREK-1 and TRAAK channels, the conversion of these C-fibres into a novel C-fibre family with a higher temperature threshold implies that mice lacking both the TREK-1 and TRAAK channels should experience an unpleasant cold-hyperalgesia at temperatures near $20^{\circ} \mathrm{C}$ or higher. This is exactly what happens as seen in the cold plate assay, in which one observes that exposure of TREK- $1^{-/-}$- $\mathrm{TRAAK}^{-/-}$mice at a temperature of $20^{\circ} \mathrm{C}$ (or $15^{\circ} \mathrm{C}$ ) is as painful as exposure at a temperature of $10^{\circ} \mathrm{C}$ for wild-type mice (Figure $5 \mathrm{~A}$ ).

In the cold-avoidance test, one observes that mice lacking both TREK-1 and TRAAK channels (but not TRAAK ${ }^{-/-}$mice) have a tendency to prefer the $30^{\circ} \mathrm{C}$ plate when the second plate is at $24^{\circ} \mathrm{C}$, and this is significant at 21,18 and $15^{\circ} \mathrm{C}$. TREK- $1^{-/-}$-TRAAK ${ }^{-/-}$mice spend $\sim 86 \%$ of their time on the plate at $30^{\circ} \mathrm{C}$ when given the choice with $21^{\circ} \mathrm{C}$. This extent of preference is reached in wild type when the choice is between 30 and $\sim 12^{\circ} \mathrm{C}$. The TREK- $1^{-/-}$mice shows more temperature discrimination than wild type at $18^{\circ} \mathrm{C}$ (Supplementary Figure 7). Therefore, the combination of TREK-1 and TRAAK channels clearly has an important function in unpleasant cold perception. In neuropathic conditions, it is clear that deletion of both TREK-1 and TRAAK channels produces a very marked cold hyperalgesia as compared with wild type at temperatures of 20 and $15^{\circ} \mathrm{C}$.

All these results taken together show the important function of TREK-1 and TRAAK channels, acting individually or together, in controlling the sensitivity, degree by degree, in response to heat and cold. Considerable phenotypic rearrangements of DRGs and C-fiber responses are observed when these channels are deleted. For example, deletion of these two channels increases the proportion of mechanosensitive C-fibers sensitive to both heat and cold from $24 \%$ in wild type to $44 \%$ (Supplementary Figure 3). The main function of TREK-1 and TRAAK as temperature-sensitive channels is to serve as silencers of partner heat-sensitive and cold-sensitive excitatory channels, such as TRPV1 and TRPM8, TRPA1 or other channels, today not clearly identified, expressed in capsaicin-insensitive heat-sensitive or menthol-insensitive cold-sensitive neurons (Figure 6). TREK-1 and TRAAK channels, when they are opened, tend to suppress pain. Their removal by gene deletion or their gradual removal by temperature variations at high or low temperatures or by regulation processes involving hormones, cytokines or neurotransmitters will make animals hypersensitive to pain. These considerations are of course very important in the search for new analgesic drugs.

It is probable that sensory depolarizing channels and TREK-1 and TRAAK channels are tightly co-localized in free nerve terminals in the skin. Our prediction is that TREK- 1 and TRAAK channels are in charge of producing a local tempera- ture-dependent control of membrane potential in sensory terminals and that local variations of membrane potential, dependent on TREK-1 and TRAAK activity, will, in turn, control the temperature sensitivity of TRP channels. Depolarization is known to sensitize TRP channels to heat or cold variations. Considerable increase of TRPV1 activity is observed at $42^{\circ} \mathrm{C}$ on depolarization, and the same is true for TRPM8 activity at $15^{\circ} \mathrm{C}$ (Voets et al, 2004). It appears therefore that a functional connection through membrane depolarization between TREK-1 and TRAAK channels and thermoTRP channels is probably essential for a fine perception of both warm and cold.

\section{Materials and methods}

Materials and methods are described briefly here. Full details are available in Supplementary data.

\section{Culture of DRG neurons and intracellular $\mathrm{Ca}^{2+}$ imaging}

Dorsal root ganglion neurons were prepared from 10- to 12 -weekold wild-type (C57Bl/6J), TREK-1 ${ }^{-1-}$, TRAAK ${ }^{-1-}$ and TREK-1 ${ }^{-1-}$. TRAAK $^{-1-}$ male mice and cultured for 2-7 days. For cell imaging, cells were loaded with Fluo-3-AM $10 \mu \mathrm{M}$. Bath was kept at $30^{\circ} \mathrm{C}$ and temperature ramps were applied locally with the thermal-probe positioned near the observation field. Images were captured every 2-5 s with an EM-CCD camera (Roper Scientific) mounted on an Observer Z.1 microscope (Zeiss, Germany), and Metafluor acquisition software (Molecular Devices). On the basis of previous electrophysiological characterization of cultured DRGs, neurons were clearly identified as globular-shaped cell bodies with a single unipolar protrusion. Fluorescence is expressed as the ratio $F / F_{0}$ and the threshold for sensitivity was set at 0.2 variation of the fluorescence ratio.

\section{Single $C$-fibre recordings}

The isolated skin-saphenous nerve preparation and single-fibre recording technique was used as described previously (Reeh, 1986) (Supplementary data).

\section{Electrophysiology}

We used the whole-cell configuration of the patch clamp technique to measure membrane potentials (current clamp) of cultured DRG neurons at $30^{\circ} \mathrm{C}$ (Supplementary data).

\section{Mice}

All experiments were performed on 20-24 g male mice of the N10F2 backcross generation to $\mathrm{C} 57 \mathrm{Bl} / 6 \mathrm{~J}$ congenic strain (Heurteaux et al, 2004). TREK1/TRAAK double-heterozygote mice were generated by crossing single knockout mice with each other (N10F1 TREK-1 $1^{-1-}$ males with N10F1 TRAAK $^{-/-}$females). TREK-1 ${ }^{-1-}$ TRAAK $^{-/-}$ mice were obtained by intercrossing double-heterozygotes. We assume the sensory neuronal network to be unchanged in the knockout mice because these mice show normal levels of motor coordination and fatigue resistance in the rotarod test (wild-type: $74.8 \pm 4.9 \mathrm{~s}, n=8$; and TREK- $1^{-/-}$-TRAAK $^{-1-}$ mice: $69.8 \pm 4.1 \mathrm{~s}$, $n=8, P=0.46$, $t$-test) and normal exploratory behaviour in the place preference test (number of midline crossing over $3 \mathrm{~min}$ when given the choice between two plates at $30^{\circ} \mathrm{C}$, wild-type mice: $17.9 \pm 1.1$ crossing, $n=8$; and TREK- ${ }^{-1-}{ }^{-T_{R A A K}}{ }^{-1-}$ mice: $17.8 \pm 1.9$ crossing, $n=8, P=0.96$, $t$-test; number of midline crossing over $3 \mathrm{~min}$ when given the choice between a plate at $30^{\circ} \mathrm{C}$ and a plate at $27^{\circ} \mathrm{C}$, wild-type mice: $11.1 \pm 1.3$ crossing, $n=8$; and TREK-1 ${ }^{-1-}$-TRAAK ${ }^{-1-}$ mice: $11.5 \pm 1.7$ crossing, $n=8$, $P=0.87, t$-test). The behavioural experiments were performed blind to the genotype, in a quiet room, by the same experimenter for a given test taking great care to minimize or avoid discomfort of the animals.

\section{Mice mechanical sensitivity}

Allodynia was assessed with calibrated von Frey filaments (0.0045-5.4950 g) (Alloui et al, 2006). Filaments were applied five times in the order of increasing stiffness, perpendicularly to the plantar surface of the hind paw and pressed until they bent. 
The first filament that evoked at least one response was assigned as the threshold.

\section{Flinch test}

Mice were acclimatized for $30 \mathrm{~min}$ in a transparent observation chamber before the subcutaneous injection on the dorsum of the hind paw of $10 \mu \mathrm{l}$ hypertonic $(2 \% \mathrm{NaCl})$ solution using a 30 -gauge needle connected to a $100 \mu \mathrm{l}$ Hamilton syringe (Alessandri-Haber et al, 2005). The time of licking and shacking of the paw was recorded for a 5 min period starting immediately after the injection. For sensitization with $\mathrm{PGE}_{2}, \mathrm{PGE}_{2}(100 \mathrm{ng}, 5 \mu \mathrm{l})$ was injected $30 \mathrm{~min}$ before the hypertonic saline.

\section{Hot-plate test}

Mice remained on the plate $\left(52-56^{\circ} \mathrm{C}\right)$ until they started licking their fore paws (latencies) (cutoff time: $20 \mathrm{~s}$ ).

\section{Cold-plate test}

After being acclimatized for $30 \mathrm{~min}$, the paw of a gently restrained mouse was applied on the surface of the cold plate set at temperatures from 5 to $18^{\circ} \mathrm{C}$ (ambient temperature $21 \pm 1^{\circ} \mathrm{C}$ ) and the time for the first brisk lift or stamp of the paw was recorded (cutoff time: $20 \mathrm{~s}$ ). Mice were trained for four consecutive days and the measure was done on the fifth day.

\section{Thermal preference test}

Two hot/cold plate analgesia metres (Bioseb, France) were placed side by side such that the adjacent thermal surfaces were enclosed in a single chamber $(34 \times 16 \mathrm{~cm})$. The temperature of each plate was controlled at $\pm 0.1^{\circ} \mathrm{C}$. The movement of the mice between the two plates was recorded with a video tracking system over 3 min by tallying the cumulative time spent on each plate. Wild type and TREK- $1^{-1-}$-TRAAK ${ }^{-1-}$ mice showed equal level of activity, with $17.9 \pm 1.1$ and $17.8 \pm 1.9$ midline crossing over $3 \mathrm{~min}$, respectively.

\section{Tail-immersion test}

The tail was immersed in a water bath until withdrawal was observed (cutoff time: $30 \mathrm{~s}$ ). Two separate withdrawal latency time determinations were averaged.

\section{References}

Abrahamsen B, Zhao J, Asante CO, Cendan CM, Marsh S, MartinezBarbera JP, Nassar MA, Dickenson AH, Wood JN (2008) The cell and molecular basis of mechanical, cold, and inflammatory pain. Science 321: 702-705

Alessandri-Haber N, Joseph E, Dina OA, Liedtke W, Levine JD (2005) TRPV4 mediates pain-related behavior induced by mild hypertonic stimuli in the presence of inflammatory mediator. Pain 118: $70-79$

Alloui A, Zimmermann K, Mamet J, Duprat F, Noel J, Chemin J, Guy N, Blondeau N, Voilley N, Rubat-Coudert C, Borsotto M, Romey G, Heurteaux C, Reeh P, Eschalier A, Lazdunski M (2006) TREK-1, a $\mathrm{K}+$ channel involved in polymodal pain perception. EMBO J 25: 2368-2376

Babes A, Zorzon D, Reid G (2004) Two populations of cold-sensitive neurons in rat dorsal root ganglia and their modulation by nerve growth factor. Eur J Neurosci 20: 2276-2282

Babes A, Zorzon D, Reid G (2006) A novel type of cold-sensitive neuron in rat dorsal root ganglia with rapid adaptation to cooling stimuli. Eur J Neurosci 24: 691-698

Bautista DM, Jordt SE, Nikai T, Tsuruda PR, Read AJ, Poblete J, Yamoah EN, Basbaum AI, Julius D (2006) TRPA1 mediates the inflammatory actions of environmental irritants and proalgesic agents. Cell 124: 1269-1282

Bautista DM, Siemens J, Glazer JM, Tsuruda PR, Basbaum AI, Stucky CL, Jordt SE, Julius D (2007) The menthol receptor TRPM8 is the principal detector of environmental cold. Nature 448: $204-208$

Bennett GJ, Xie YK (1988) A peripheral mononeuropathy in rat that produces disorders of pain sensation like those seen in man. Pain 33: 87-107

\section{Carrageenan-induced inflammatory hyperalgesia}

Carrageenan ( $2 \%$ in saline) was injected subcutaneously $(20 \mu \mathrm{l})$ into the right hind paw. Mice were tested for thermal sensitivity by measuring withdrawal latencies of right hind paw immersed in a water bath at $46^{\circ} \mathrm{C}$.

\section{Unilateral peripheral mononeuropathy}

Unilateral peripheral mononeuropathy was induced in mice anaesthetized with sodium pentobarbital $(60 \mathrm{mg} / \mathrm{kg}$, i.p.) with three chromic gut $(4-0)$ ligatures tied loosely (with about $1 \mathrm{~mm}$ spacing) around the common sciatic nerve (Bennett and Xie, 1988). The nerve was constricted to a barely discernable degree, so that circulation through the epineurial vasculature was not interrupted. Heat sensitivity was tested 12 days after surgery by immersing the hind paw ipsilateral to the partial nerve ligature of gently restrained mice in a water bath at $46^{\circ} \mathrm{C}$. Mice were trained for $4-5$ sessions. For test of cold sensitivity, 12 days after surgery, neuropathic mice were placed on a cold plate and the total time the mouse lifted the paw ipsilateral to the partial nerve ligature was measured over $3 \mathrm{~min}$.

\section{Statistical analysis}

All statistical analysis was done with the Graphpad Prism4 software. The results are expressed as the mean \pm s.e.m. All statistical tests and significance levels are in the text.

\section{Supplementary data}

Supplementary data are available at The EMBO Journal Online (http://www.embojournal.org).

\section{Acknowledgements}

We especially thank Eric Lingueglia for reading the manuscript. We thank Frédéric Brau for the image analysis routine, Franck Aguila for figure presentation and Martine Jodar for cultures of DRG neurons. This work was supported by the University of NiceSophia Antipolis and the University of Auvergne Clermont1, CNRS, INSERM, ANR Project Analgesia and Ion channel in Nociceptive Pathways, the Association pour la Recherche sur le Cancer (ARC-INCa), the Association Française contre les Myopathies (AFM), and the Institut Paul Hammel.

Caterina MJ, Leffler A, Malmberg AB, Martin WJ, Trafton J, Petersen-Zeitz KR, Koltzenburg M, Basbaum AI, Julius D (2000) Impaired nociception and pain sensation in mice lacking the capsaicin receptor. Science 288: 306-313

Chemin J, Girard C, Duprat F, Lesage F, Romey G, Lazdunski M (2003) Mechanisms underlying excitatory effects of group I metabotropic glutamate receptors via inhibition of $2 \mathrm{P}$ domain $\mathrm{K}+$ channels. EMBO J 22: 5403-5411

Chemin J, Patel AJ, Duprat F, Lauritzen I, Lazdunski M, Honore E (2005) A phospholipid sensor controls mechanogating of the $\mathrm{K}+$ channel TREK-1. EMBO J 24: 44-53

Colburn RW, Lubin ML, Stone Jr DJ, Wang Y, Lawrence D, D’Andrea MR, Brandt MR, Liu Y, Flores CM, Qin N (2007) Attenuated cold sensitivity in TRPM8 null mice. Neuron 54: 379-386

Dhaka A, Murray AN, Mathur J, Earley TJ, Petrus MJ, Patapoutian A (2007) TRPM8 is required for cold sensation in mice. Neuron 54: 371-378

Dhaka A, Viswanath V, Patapoutian A (2006) Trp ion channels and temperature sensation. Annu Rev Neurosci 29: 135-161

Fajardo O, Meseguer V, Belmonte C, Viana F (2008) TRPA1 channels mediate cold temperature sensing in mammalian vagal sensory neurons: pharmacological and genetic evidence. J Neurosci 28: 7863-7875

Fink M, Lesage F, Duprat F, Heurteaux C, Reyes R, Fosset M, Lazdunski M (1998) A neuronal two P domain K+ channel stimulated by arachidonic acid and polyunsaturated fatty acids. EMBO J 17: 3297-3308

Heurteaux C, Guy N, Laigle C, Blondeau N, Duprat F, Mazzuca M, Lang-Lazdunski L, Widmann C, Zanzouri M, Romey G, 
Lazdunski M (2004) TREK-1, a K + channel involved in neuroprotection and general anesthesia. EMBO J 23: 2684-2695

Julius D, Basbaum AI (2001) Molecular mechanisms of nociception. Nature 413: 203-210

Kang D, Choe C, Kim D (2005) Thermosensitivity of the two-pore domain $\mathrm{K}+$ channels TREK-2 and TRAAK. J Physiol 564 (Part 1): $103-116$

Kang D, Kim D (2006) TREK-2 (K2P10.1) and TRESK (K2P18.1) are major background $\mathrm{K}+$ channels in dorsal root ganglion neurons. Am J Physiol Cell Physiol 291: C138-C146

Karashima Y, Damann N, Prenen J, Talavera K, Segal A, Voets T, Nilius B (2007) Bimodal action of menthol on the transient receptor potential channel TRPA1. J Neurosci 27: 9874-9884

Karashima Y, Talavera K, Everaerts W, Janssens A, Kwan KY, Vennekens R, Nilius B, Voets T (2009) TRPA1 acts as a cold sensor in vitro and in vivo. Proc Natl Acad Sci USA 106: 1273-1278

Kirchhoff C, Leah JD, Jung S, Reeh PW (1992) Excitation of cutaneous sensory nerve endings in the rat by 4-aminopyridine and tetraethylammonium. J Neurophysiol 67: 125-131

Kwan KY, Allchorne AJ, Vollrath MA, Christensen AP, Zhang DS, Woolf CJ, Corey DP (2006) TRPA1 contributes to cold, mechanical, and chemical nociception but is not essential for hair-cell transduction. Neuron 50: 277-289

Lewin GR, Moshourab R (2004) Mechanosensation and pain. J Neurobiol 61: 30-44

Macpherson LJ, Hwang SW, Miyamoto T, Dubin AE, Patapoutian A, Story GM (2006) More than cool: promiscuous relationships of menthol and other sensory compounds. Mol Cell Neurosci 32: 335-343

Maingret F, Fosset M, Lesage F, Lazdunski M, Honore E (1999a) TRAAK is a mammalian neuronal mechano-gated $\mathrm{K}+$ channel. J Biol Chem 274: 1381-1387

Maingret F, Lauritzen I, Patel AJ, Heurteaux C, Reyes R, Lesage F, Lazdunski M, Honore E (2000a) TREK-1 is a heat-activated background $\mathrm{K}(+)$ channel. EMBO J 19: 2483-2491

Maingret F, Patel AJ, Lesage F, Lazdunski M, Honore E (1999b) Mechano- or acid stimulation, two interactive modes of activation of the TREK-1 potassium channel. J Biol Chem 274: 26691-26696

Maingret F, Patel AJ, Lesage F, Lazdunski M, Honore E (2000b) Lysophospholipids open the two-pore domain mechanogated $\mathrm{K}(+)$ channels TREK-1 and TRAAK. J Biol Chem 275: 10128-10133

Matsuka Y, Spigelman I (2004) Hyperosmolar solutions selectively block action potentials in rat myelinated sensory fibers: implications for diabetic neuropathy. J Neurophysiol 91: 48-56

Medhurst AD, Rennie G, Chapman CG, Meadows H, Duckworth MD, Kelsell RE, Gloger II, Pangalos MN (2001) Distribution analysis of human two pore domain potassium channels in tissues of the central nervous system and periphery. Brain Res Mol Brain Res 86: 101-114

Moqrich A, Hwang SW, Earley TJ, Petrus MJ, Murray AN, Spencer KS, Andahazy M, Story GM, Patapoutian A (2005) Impaired thermosensation in mice lacking TRPV3, a heat and camphor sensor in the skin. Science 307: 1468-1472
Munns C, Alqatari M, Koltzenburg M (2007) Many cold sensitive peripheral neurons of the mouse do not express TRPM8 or TRPA1. Cell Calcium 41: 331-342

Murbartian J, Lei Q, Sando JJ, Bayliss DA (2005) Sequential phosphorylation mediates receptor- and kinase-induced inhibition of TREK-1 background potassium channels. J Biol Chem 280: 30175-30184

Patel AJ, Honore E, Lesage F, Fink M, Romey G, Lazdunski M (1999) Inhalational anesthetics activate two-pore-domain background $\mathrm{K}+$ channels. Nat Neurosci 2: 422-426

Patel AJ, Honore E, Maingret F, Lesage F, Fink M, Duprat F, Lazdunski M (1998) A mammalian two pore domain mechanogated S-like K + channel. EMBO J 17: 4283-4290

Reeh PW (1986) Sensory receptors in mammalian skin in an in vitro preparation. Neurosci Lett 66: 141-146

Reid G (2005) ThermoTRP channels and cold sensing: what are they really up to? Pflugers Arch 451: 250-263

Reid G, Flonta M (2001a) Cold transduction by inhibition of a background potassium conductance in rat primary sensory neurones. Neurosci Lett 297: 171-174

Reid G, Flonta ML (2001b) Cold current in thermoreceptive neurons. Nature 413: 480

Sandoz G, Tardy MP, Thummler S, Feliciangeli S, Lazdunski M, Lesage F (2008) Mtap2 is a constituent of the protein network that regulates twik-related $\mathrm{K}+$ channel expression and trafficking. J Neurosci 28: 8545-8552

Sandoz G, Thummler S, Duprat F, Feliciangeli S, Vinh J, Escoubas P, Guy N, Lazdunski M, Lesage F (2006) AKAP150, a switch to convert mechano-, $\mathrm{pH}$ - and arachidonic acid-sensitive TREK $\mathrm{K}(+)$ channels into open leak channels. EMBO J 25: 5864-5872

Story GM, Peier AM, Reeve AJ, Eid SR, Mosbacher J, Hricik TR, Earley TJ, Hergarden AC, Andersson DA, Hwang SW, McIntyre P, Jegla T, Bevan S, Patapoutian A (2003) ANKTM1, a TRP-like channel expressed in nociceptive neurons, is activated by cold temperatures. Cell 112: 819-829

Stucky CL, Lewin GR (1999) Isolectin B(4)-positive and -negative nociceptors are functionally distinct. J Neurosci 19: 6497-6505

Treede RD, Meyer RA, Raja SN, Campbell JN (1995) Evidence for two different heat transduction mechanisms in nociceptive primary afferents innervating monkey skin. J Physiol 483 (Part 3): 747-758

Viana F, de la Pena E, Belmonte C (2002) Specificity of cold thermotransduction is determined by differential ionic channel expression. Nat Neurosci 5: 254-260

Voets T, Droogmans G, Wissenbach U, Janssens A, Flockerzi V, Nilius B (2004) The principle of temperature-dependent gating in cold- and heat-sensitive TRP channels. Nature 430: 748-754

Wetzel C, Hu J, Riethmacher D, Benckendorff A, Harder L, Eilers A, Moshourab R, Kozlenkov A, Labuz D, Caspani O, Erdmann B, Machelska H, Heppenstall PA, Lewin GR (2007) A stomatindomain protein essential for touch sensation in the mouse. Nature 445: 206-209

Woodbury CJ, Zwick M, Wang S, Lawson JJ, Caterina MJ, Koltzenburg M, Albers KM, Koerber HR, Davis BM (2004) Nociceptors lacking TRPV1 and TRPV2 have normal heat responses. J Neurosci 24: 6410-6415 